\title{
ANAP

\section{PERCEPÇÃO AMBIENTAL: UMA FERRAMENTA PARA DISCUTIR O AMBIENTE URBANO}

\author{
Aquélis Armiliato Emer ${ }^{1}$
}

Hieda Maria Pagliosa Corona ${ }^{2}$

RESUMO: Este artigo tem como objetivo discutir os reflexos da forma de desenvolvimento atual e do crescente processo de urbanização sobre a qualidade de vida da população, bem como o distanciamento da relação homem-natureza dentro das cidades. A percepção da limitação do atual modelo de desenvolvimento das cidades e da necessidade de formação de sujeitos-atores na sociedade conduz à constatação de que o saber interdisciplinar é fundamental para tratar da complexidade dos problemas urbanos. Há, nesse contexto, a necessidade de manutenção ou revitalização de áreas verdes nos centros urbanos para o aumento da qualidade de vida dos habitantes das cidades e para o aumento da sustentabilidade urbana.

Palavras-chave: Cidade. Sujeito-ator. Sustentabilidade.

\section{INTRODUÇÃO}

\footnotetext{
${ }^{1}$ Engenheira Agrônoma, mestranda em Desenvolvimento Regional pela Universidade Tecnológica Federal do Paraná.

${ }^{2}$ Socióloga, doutora em Meio Ambiente e Sociedade, professora da Universidade Tecnológica Federal do Paraná.
} 


\section{ANAP Brasil ISSN 1904-3240 V. 6, n. 7}

\section{R E V ISTA C I E N T ÍF I C A JULHO/2013}

O processo de construção de ambientes urbanos mais sustentáveis passa pela revitalização das áreas verdes, essenciais na diminuição dos impactos ambientais causados pela impermeabilização dos solos e pela desflorestação.

As iniciativas de constituição de ambientes urbanos mais saudáveis tornam-se mais efetivas com a interação e a participação da sociedade junto ao processo construtivo, restabelecendo uma relação entre sociedade e natureza perdida em função dos princípios que a modernidade capitalista adotou ao longo da história.

A percepção da sociedade urbana frente à limitação do processo de desenvolvimento atual pode influenciar de forma decisiva para que ela se constitua de agentes atuantes de mudança, tornando-se verdadeiramente atores sociais.

A correta percepção dos problemas ambientais urbanos nos remete a problematizar a complexidade e a abrangência que estes determinam para sua resolução. Dessa forma, cabe ressaltar a importância de diferentes olhares e saberes frente a problemas urbanos e seu planejamento intersetorial abrangendo a participação da coletividade, tratando de suas especificidades com olhar multidirecional.

Leff (2009) expõe que o saber ambiental problematiza o conhecimento fragmentado em disciplinas e a administração setorial do desenvolvimento, para construir um campo de conhecimentos teóricos e práticos orientado para a rearticulação das relações sociedade-natureza.

O intercambio de conhecimentos científicos e técnicos aliados ao conhecimento empírico e tradicional das populações permite um olhar mais abrangente e significativo frente à complexidade envolvida nos problemas de ordem socioambiental como um todo.

Sendo assim, o objetivo deste artigo é resgatar alguns conceitos historicamente importantes na perspectiva ambiental e discutir o desenvolvimento urbano estabelecido pelos padrões da modernidade. 


\section{ANAP Brasil \\ ISSN 1904-3240 v. 6, n. 7}

\section{A CONSTRUÇÃO DO SUJEITO-ATOR DENTRO DA SOCIEDADE DE RISCO}

Os atuais padrões de desenvolvimento têm se mostrado cada vez mais fragilizados e apresentam sinais que precisam ser modificados. A falta de sustentabilidade do presente modelo faz com que a sociedade passe a se questionar e refletir sobre padrões de desenvolvimento menos consumistas e individualistas que permitam provocar mudanças efetivas para a sustentabilidade socioambiental.

Segundo Leff (2009), a degradação ambiental se revela como sintoma de uma crise de civilização, marcada pelo modelo de modernidade regido pelo predomínio de desenvolvimento da razão tecnológica sobre a organização da natureza.

Conforme Giddens (1997) a partir do momento que a sociedade torna-se reflexiva, ela constitui um tema e um problema para ela própria. Para o autor, a modernização reflexiva é um conceito que se aplica a autoconfrontação, com o modelo de desenvolvimento da sociedade moderna e suas consequências.

Contudo, na maioria dos casos, a autoconfrontação sobre os problemas de desenvolvimento só ocorre após estes terem sido percebidos ou até mesmo ultrapassado os limites de determinado modelo, e seus reflexos passarem a fazer parte do cotidiano, ou seja, após o aparecimento do que Giddens chama de sociedades de risco.

Para Giddens (1997) a sociedade de risco surge na continuidade dos processos de modernização autônoma que se apresenta indiferente aos seus próprios efeitos e ameaças. A sociedade de risco indica um estagio da modernidade em que as ameaças produzidas até então no caminho da sociedade industrial, apontam a autolimitação daquela forma de desenvolvimento, sendo necessário redeterminar os padrões atingidos até dado momento, levando em conta as ameaças potenciais.

No entanto, conforme Steffen (2002) a percepção de riscos pela sociedade ocorre de formas muito variadas de acordo com o campo de abrangência em que os 


\section{ANAP Brasil \\ ISSN 1904-3240 V. 6, n. 7}

\section{R E V I S T A C I E N T ÍF I C A JULHO/2013}

riscos são esperados ou prováveis, sendo, portanto, imprevisíveis as reações públicas para dado acontecimento.

Hannigan (1995) coloca ainda que a percepção do risco pela sociedade sofre influências culturais e históricas, assim como a percepção individual é de certa forma criada pelo circulo social de cada pessoa.

Conforme Steffen (2002), essa diferença de percepção da sociedade demonstra que o nível das reações públicas aos riscos não parece estar relacionado à natureza do risco ou acidente, à severidade do possível dano, às consequências em longo prazo ou à extensão geográfica, assim como não reflete a eficiência ou a ineficiência no gerenciamento de determinado riscos.

As diferenças na percepção do risco podem estar associadas em parte ao quanto a sociedade está envolvida e exposta a determinado perigo. Ou seja, problemas ambientais globais podem aparentemente demonstrar distanciamento e por isso são percebidos como improváveis de atingir de fato determinada população. Somente a partir do momento que o risco se torna mais visível e comprovável para a sociedade, esta passa a perceber e temer seus impactos.

De acordo com Leff (2009), o despertar da consciência ambiental pelo homem, coloca todo o indivíduo como sujeito moral para construir uma nova racionalidade social.

A conscientização da sociedade é explicada por Touraine (1994) como a formação do sujeito social, que nada mais é que a passagem do indivíduo por um processo de "subjetivação", ou seja, a transformação do indivíduo em sujeito. O sujeito, para Touraine (1994), é a vontade de um indivíduo de agir e ser reconhecido como ator que se insere nas relações sociais, transformando-as, sendo capaz de modificar o ambiente no qual está inserido. Para Touraine (1994), o sujeito e o autor são inseparáveis e resistem conjuntamente a um individualismo que restitui a superioridade à lógica do sistema sobre o ator, reduzindo-o à procura racional.

O espírito crítico dos indivíduos dentro da sociedade, frente ao processo de modernidade, determina que estes sejam capazes de se reconhecer sujeitos-atores no 


\section{ANAP Brasil \\ ISSN 1904-3240 V. 6, n. 7}

\section{R E V IST A C I E N T ÍF I C A JULHO/2013}

ambiente onde se inserem, e sejam aptos a pensar e criar ações para a construção de formas de desenvolvimentos mais sustentáveis.

Touraine (1994) exemplifica que a melhor definição da modernidade não é o progresso das técnicas, nem o individualismo crescente dos consumidores, mas a exigência de liberdade e sua defesa contra tudo o que transforma o ser humano em instrumento, em objeto, ou em absoluto estranho.

Conforme Leff (2009), a questão ambiental problematiza as próprias bases de produção e aponta para a desconstrução do paradigma econômico da modernidade e para a construção de futuros possíveis, fundados nos limites das leis da natureza, nos potenciais ecológicos, na produção de sentidos sociais e na criatividade humana.

É também nesse sentido que Touraine (1994) faz uma crítica ao que chama de sociedade programada, onde os indivíduos perdem seu poder de gestão consciente, sendo reduzidos a consumidores, recurso humano ou simplesmente um alvo.

É possível que as sociedades futuras sejam cada vez mais impulsionadas a refletir sobre suas práticas e se tornem cada vez mais críticas, no sentido de não serem somente indivíduos manipuláveis dentro do ambiente em que vivem, mas que cada vez mais possam e queiram estar ativos dentro da sociedade somando e compartilhando conhecimentos e experiências para que de fato seja alcançado o desenvolvimento.

\section{DESENVOLVIMENTO URBANO X MEIO AMBIENTE}

Atualmente mais de metade da população mundial vive nas cidades. Esse comportamento se reflete em boa parte dos municípios brasileiros. O deslocamento e a concentração da população nas áreas urbanas, constituída historicamente, levaram ao distanciamento e exclusão das relações existentes entre a natureza e o homem urbano.

A paisagem de ambientes naturais é produto da ação e da interação de vários fatores, como, solo, relevo, clima, cobertura vegetal, temperatura e dos organismos vivos, ao longo do tempo. 


\section{ANAP

No decorrer da história, as paisagens naturais foram sendo gradativamente transformadas pelas mãos humanas que passaram a se apoderar de seus recursos para subsistência. Contudo, com o transcorrer dos períodos e com a modernização, os recursos e paisagens naturais foram sendo cada vez mais modificados e explorados pela forma de desenvolvimento exploratório e capitalista que a sociedade adotou.

Ao analisar as paisagens atuais, muito do que vemos é resultado de ações antrópicas promovidas pelo desenvolvimento industrial e urbano pelo qual a sociedade progrediu ao longo das últimas gerações.

Conciliar a crescente expansão das cidades com a preservação do meio ambiente é, sobretudo, um grande desafio nos tempos modernos. Mesmo com o avanço dos conhecimentos científicos e das tecnologias, o adequado desenvolvimento urbano passa pela conscientização e pela percepção dos seus habitantes de sua importância frente às questões ambientais urbanas, sendo mais importante que qualquer técnica que se pretenda aplicar.

Touraine (1994) coloca que a ciência e a técnica foram por muito tempo símbolo da modernidade, mas que existe a necessidade da complementação desses fatores através do ser humano. Para o autor, conceitos como racionalização e subjetivação, ao mesmo tempo em que se contrapõem, se complementam, de forma que não existe técnica ou ciência que sejam de fato efetivas sem a participação e o entendimento do sujeito.

Hannigan (1995) destaca a importância do conhecimento vulgar acumulado pelas populações locais através das experiências cotidianas na percepção e nas formulações dos problemas ambientais e da importância que a mobilização social tem para obtenção e reconhecimento público para determinada ação. Corroborando com isso, Touraine (1994) coloca que a modernidade de uma sociedade pode ser medida pela capacidade que esta tem de se reapropriar das experiências humanas afastadas no tempo ou espaço. 


\section{ANAP Brasil \\ ISSN 1904-3240 V. 6, n. 7}

\section{R E V IST A C I E N T ÍF I C A JULHO/2013}

De acordo com Tuan (1980), o modo como as pessoas percebem o meio ambiente varia grandemente com suas experiências, seus antecedentes socioeconômicos e sua cultura, assim como suas atitudes podem mudar ao longo do tempo.

É nesse sentido que Hannigan (1995) discute que todas as definições de risco são parcialmente corretas, visto que culturas diferentes, tradições históricas, a forma de organização política e administrativa das sociedades atribuem pesos diferentes aos acontecimentos. A diferença na percepção dos riscos é muitas vezes entendida como um problema de subjetividade versus objetividade (STEFFEN, 2002).

Dessa forma, os riscos e consequências inerentes ao meio ambiente parecem desvinculados do ambiente urbano, pela noção predominante na sociedade de que os elementos naturais estão muito mais atrelados e dependentes das modificações e depredações dos ambientes rurais.

A expansão das urbes e a concentração da população nas cidades fizeram com que a percepção da relação homem-natureza fosse de certa forma muito diminuída ou até mesmo eliminada do cotidiano da maioria da sociedade. Com isso, a relação direta com a natureza acaba ficando restrita a um número mínimo de trabalhadores que continuam a cultivar, trabalhar e explorar os recursos no meio natural.

Contudo, os elementos naturais, como o solo, a água, as áreas verdes, constituem elementos indispensáveis à estruturação de qualquer cidade moderna e a falta desses elementos ou seu uso e manejo inadequados acarretam no empobrecimento na paisagem urbana, intensificando as possibilidades de riscos ambientais, sociais e econômicos pelos quais acabamos sendo indiscriminadamente atingidos.

Conforme Foster (2005), Marx afirmava que o homem vive e é parte da natureza, e por isso mesmo sua vida física e mental está vinculada a ela, devendo estabelecer uma relação constante com a mesma para sobreviver. Nesse sentido, a busca de ambientes urbanos mais sustentáveis sem dúvida passa pela reintegração da natureza a esses ambientes. 


\section{ANAP

Segundo Foster (2005), Marx coloca que a expansão da forma capitalista de produção foi o que concentrou a população nas cidades, sendo responsável por perturbar a interação metabólica entre o homem e a terra, impedindo a devolução ao solo de seus elementos constituintes; foi o que Marx chamou de falha metabólica.

De acordo com Foster (2005), Marx utilizou o termo metabolismo para descrever a relação do homem com a natureza através do trabalho, uma forma de apropriação da natureza para satisfazer suas necessidades. Marx também utilizou o conceito para descrever o conjunto complexo, dinâmico, interdependente das necessidades e das relações geradas e consequentemente reproduzidas de forma alienada pelo capitalismo. Assim, a população mundial no decorrer da história foi gradativamente se deslocando para as cidades com o propósito de conseguir melhores condições de vida e deixando de lado a relação ativa que constituía junto com a natureza.

O grande deslocamento da população rural aliado à falta de planejamento nas cidades também pode ser considerada uma "falha metabólica", que ocasionou uma série de problemas de ordem ambiental e social que acabaram por limitar a qualidade de vida da população urbana.

Os entraves do desenvolvimento urbano ao mesmo tempo em que parecem ser individualizados, aos poucos se mostram interligados e inseparáveis, exigindo ações conjuntas para sua solução.

A variedade e complexidade de fatores que estão envolvidos no desenvolvimento urbano tornam o diálogo entre diversas correntes de conhecimento necessário e indispensável. Os diferentes olhares e focos que cada especialidade apresenta ao observar um problema geram uma complementaridade de saberes necessários para os sistemas urbanos.

Leff (2009) coloca que a gestão ambiental do desenvolvimento sustentável exige novos conhecimentos interdisciplinares e seu planejamento intersetorial constitui um convite aos cidadãos a participar na produção de suas condições de existência e em seus projetos de vida. 


\section{ANAP Brasil \\ ISSN 1904-3240 v. 6, n. 7}

\section{R E V IST A C I E N TÍF I C A $\quad$ JULHO/2013}

Colaborando neste contexto Melazo, (2005, p. 4 ) coloca que:

O grande desafio da sustentabilidade urbana reside na capacidade de tratar as cidades e o seu meio natural em sua especificidade e em toda a sua complexidade, através de uma abordagem multidimensional e interdisciplinar que permita a superação dos desequilíbrios resultantes dessas trocas desiguais, sejam elas internas ou externas à cidade.

O princípio de sustentabilidade surge no contexto da globalização como marca de um limite e o sinal que reorienta o processo civilizatório da humanidade (LEFF, 2009).

Guimarães (2001) propõem um novo paradigma de desenvolvimento onde o ser humano estaria inserido no centro do processo, considerando o crescimento um meio e não um fim, oferecendo oportunidade de vida a gerações atuais e futuras.

O que se pretende é a participação ativa e crítica da sociedade sobre formas de desenvolvimento social e humano, colocando os interesses comuns acima dos interesses individuais e do crescimento econômico.

Touraine (1994, p. 249) expõe que o sujeito ator só existe como "movimento social", como contestação da lógica da ordem, tome esta uma forma utilitarista ou seja simplesmente a busca da integração social. Conforme o autor, a modernidade depende da formação de um sujeito com responsabilidades perante si e também com a sociedade.

A crise ambiental, segundo Leff (2009), veio questionar a racionalidade dos paradigmas teóricos que impulsionaram e legitimaram o crescimento econômico negando a natureza, de forma que a sustentabilidade ecológica aparece como um critério normativo para a reconstrução da ordem econômica, como condição para a sobrevivência humana e um suporte para chegar a um desenvolvimento duradouro, sobretudo questionando as próprias bases da produção.

Para Leff (2009), com a percepção da crise ecológica foi sendo configurado um conceito de ambiente como uma nova abordagem de desenvolvimento humano, que reintegra os valores potenciais na natureza, as externalidades sociais, os saberes subjugados e a complexidade do mundo negado pela racionalidade mecanicista, simplificadora, unificadora e fragmentada que conduziu o processo de modernização. 


\section{ANAP

Steffen (2002) colabora neste contexto colocando que mesmo dentro da comunidade científica a percepção de riscos é de certo modo construída socialmente e que manifestações públicas dependem de fenômenos sociológicos e institucionais.

O processo de modernização da sociedade conduziu a concentração da população mundial nas cidades e por isso mesmo um novo processo de desenvolvimento deve contemplar ações que focalizem a sociedade urbana, mostrando que esta é parte integrante do meio ambiente e que não deve ser isenta de responsabilidade frente à chamada crise ambiental.

A centralização da população em áreas urbanas também reúne muito dos problemas ambientais e sociais da sociedade moderna, representados grandemente pela pobreza e pelos impactos ambientais. Entre os impactos que mais se refletem na sociedade pela urbanização estão: a poluição produzida por carros, indústrias e fábricas; impermeabilização dos solos e remoção da vegetação.

$O$ excesso de pavimentação nos solos e a desflorestação acabam por diminuir ou anular a capacidade das águas pluviais de se infiltrarem no solo urbano e com isso manter o funcionamento do ciclo hidrológico normalmente. A falta de infiltração de água no solo acarreta no aumento do escoamento superficial, que em eventos extremos, como precipitações intensas, podem ocasionar o alagamento de ruas e enchentes provocando sérios prejuízos econômicos, sociais e ambientais.

A função antes exercida pelo solo em ambientes naturais de absorver e drenar as águas pluviais para os rios e lençóis freáticos, foi, com o desenvolvimento e crescimento das cidades, pouco a pouco sendo substituída pelos sistemas de canalização. Esse processo a princípio se torna bastante efetivo, pois evita 0 acúmulo de água nas ruas. Contudo, se torna inútil, pois que em eventos de chuva intensa acaba por concentrar a água drenada em locais pontuais, apenas transferindo o problema da inundação para outras áreas.

Neste contexto, atualmente existe uma dificuldade muito grande da população e do próprio poder público de visualizar a dependência e a sistematicidade envolvida 


\section{ANAP

dentro da cidade, e a grande dependência existente de elementos naturais como reguladores das adversidades encontradas dentro do urbano. É necessário que se compreenda que por si só as tecnologias e o desenvolvimento científico, reflexos da modernização, não são capazes de combater ou anular os riscos e as adversidades existentes dentro do urbano, e que espaços verdes constituem uma estratégia considerável para atenuação dos impactos causados pela urbanização.

Para Giddens (1997) a desorientação que se expressa na sensação de que não se pode obter conhecimento sistemático sobre a organização social é resultante do entendimento que a própria sociedade tem de não compreender completamente os eventos e que estes estão fora de seu controle.

Isso se reflete na falta de participação ou exclusão da população da construção da sociedade, justamente pela compreensão de não se ter a visão e o conhecimento necessário para contribuir socialmente. Aliado a isso, a intensificação da vida urbana cotidiana e ao mesmo tempo o afastamento e a alienação do espaço e do ambiente que nos cerca, contribui para essa exclusão. Conforme Giddens (1997), os modos de vida produzidos pela modernidade são muito diferentes dos tipos tradicionais de ordem social ocorridos até então no que compreende a extencionalidade e também a intencionalidade.

A visualização da paisagem das cidades atuais remete às características próprias da vida moderna, capitalista e urbana, que a sociedade como um todo vem seguido, ou seja, a tendência a utilização de áreas impermeáveis e a exclusão de elementos naturais como as árvores visam, acima de tudo, tornar a vida mais prática, evitar trabalhos adicionais e tornar mais rápidas as atividades extras ao trabalho assalariado.

Conforme Monico (2001), constata-se atualmente que existe nas cidades, uma preocupação excessiva em eliminar elementos e fatores que possam representar "sujeira"; sinais e consequências disso são quintais e passeios públicos cimentados e completamente impermeabilizados. Entretanto, essa atitude pode causar consequências 


\section{ANAP

proporcionais ao tamanho da indiferença que a população tem em relação a problemas comuns como o alagamento de ruas e as enchentes.

Neste contexto, a conscientização e percepção da sociedade frente a problemas comuns são extremamente importantes para que esta compreenda sua função e a necessidade de sua participação para abrandar os impactos ambientais gerados pelos padrões do desenvolvimento moderno.

Para Melazo (2005, p. 50)

A Educação Ambiental aliada à Percepção Ambiental devem ter como objetivo, a transmissão de conhecimentos e a compreensão dos problemas ambientais e consequentemente provocar uma maior sensibilização das pessoas a respeito da preservação dos recursos naturais, bem como a prevenção de riscos de acidentes ambientais e correção de processos que afetam a qualidade de vida nos centros urbanos.

Conforme Leff (2009), a racionalidade ambiental integra os princípios éticos, as bases materiais, os instrumentos técnicos e jurídicos e as ações orientadas para a gestão democrática e sustentável do desenvolvimento. Complementa colocando que a racionalidade ambiental não é a extensão da lógica do mercado à capitalização da natureza, mas a resultante de um conjunto de significações, normas, valores, interesses e ações socioculturais.

A socialização da gestão urbana permite a reaproximação e a criação de valores ambientais também por parte da população que vive nas cidades. Não se trata de eliminar brutalmente o padrão atual, mas trabalhar e construir modelos que sejam integradores da natureza, partindo para um desenvolvimento mais sustentável também no ambiente urbano.

Para Leff (2009), o desenvolvimento sustentável vai além do propósito de capitalizar a natureza e de ecologizar a ordem econômica. A sustentabilidade ambiental implica um processo de socialização da natureza e o manejo comunitário dos recursos, fundados em princípios de diversidade ecológica e cultural. 


\section{ANAP Brasil \\ ISSN 1904-3240 V. 6, n. 7}

\section{R E V IS T A C I E N T Í F I C A JULHO/2013}

\section{INTEGRAÇÃO DA SOCIEDADE URBANA COM A NATUREZA}

O crescimento acelerado das cidades tem provocado inúmeros impactos aos ambientes naturais. Muito disso se deve à falha de planejamento urbanístico que se preocupa mais com estruturas construídas e pouco esforço mobiliza para manter e conservar ambientes naturais mediadores dos impactos ambientais provocados pela urbanização.

O predomínio de áreas construídas de certa forma ignora as necessidades de manter espaços capazes de manter viva e ativa a relação homem-natureza. A natureza passa a ser percebida, quando percebida, como algo distante e separada da vida urbana (MONICO, 2001).

Monico (2001) coloca as árvores como os principais elementos de ligação entre os habitantes urbanos e a natureza, e que estas passam a disputar espaço na paisagem com outros elementos de caráter prático como postes, fiação elétrica e telefônica e calçadas.

A vegetação urbana - representada pela presença de arborização em parques e jardins, em áreas privadas ou nas ruas e avenidas das cidades - constitui a principal forma de inclusão da natureza no cotidiano dos habitantes da cidade.

Entretanto, mesmo que a arborização seja a principal representação da natureza na sociedade urbana, esta relação é um tanto quanto distanciada e ignorada por muitos habitantes urbanos, pois o planejamento, construções e gerenciamento desses espaços quase sempre ficam a cargo das administrações públicas, representadas por seus técnicos, legisladores e políticos. Neste sentido, de acordo com Monico (2001) a população acabou sendo exteriorizada do processo, criando um distanciamento da população sobre o processo construtivo e decisório frente às questões do meio urbano.

Conforme Melazo (2005), os ambientes, sejam eles naturais ou construídos, são percebidos de acordo com o grau de importância e as experiências de cada individuo, que passam a atribuir valores e significados para esses locais. Sendo assim, o 


\section{ANAP

distanciamento do processo construtivo e decisório passa cada vez mais a afastar a relação homem-natureza dentro do urbano, tornando a população uma mera expectadora do processo.

Leff (2009) contribui com esse pensamento afirmando que a racionalidade social está orientada pelos fins do progresso e pela eficiência, o que levou à desvalorização da natureza e à degradação dos valores humanos.

"Todas as formas de vida social são parcialmente constituídas pelo conhecimento que os atores têm dela" (GIDDENS, 1991, p.45). A construção do conhecimento é gerada de forma mais efetiva quando se participa do processo e se tem a compreensão das limitações e das possibilidades, assim como, aumenta-se o vínculo e a concepção de todo o processo.

Neste sentido Touraine (1994, p. 216) coloca que "a imagem da sociedade moderna é a de uma sociedade sem atores". Nas cidades essa imagem é ainda mais expressiva, justamente pela falta de participação dos indivíduos na construção dos bens públicos de uso comum, que acabam se refletindo no distanciamento cada vez maior do homem urbano com o ambiente do qual faz parte, e no aumento do hiato entre o homem urbano e a natureza.

O resgate da consciência e dos valores humanos frente aos problemas ambientais da sociedade moderna é ponto de partida para um desenvolvimento e um crescimento mais sustentável em todas as suas esferas. Essa evolução passa pela percepção dos problemas ambientais e pela racionalização da sociedade.

Touraine (1994) expõe que a modernidade se dá pela passagem de uma concepção centralizada da vida social para uma concepção bipolar, portanto, para a gestão de relações ao mesmo tempo de complementaridade e de oposição entre a subjetivação e a racionalização.

Para Melazo (2005), cada indivíduo percebe, reage e responde diferentemente frente às ações sobre o meio, de forma que a percepção ambiental visa compreender 


\section{ANAP Brasil \\ ISSN 1904-3240 V. 6, n. 7}

\section{R E V I S T A C I E N T Í F I C A JULho/2013}

melhor as relações entre o homem e o ambiente no qual vive, suas expectativas, satisfações e insatisfações, valores e condutas.

A busca de avanços e soluções relacionadas à preservação e conservação dos recursos naturais passa pela percepção do individuo de sua responsabilidade frente a problemas de ordem local e global. Conciliar o crescimento e a expansão das cidades com a preservação do meio ambiente, não é uma missão e sim uma obrigação do poder público e dos cidadãos para com as futuras gerações.

A expressividade da ação antrópica no meio urbano exige olhares e atitudes convergentes para amenizar seus efeitos sobre a natureza, pois as cidades são sistemas que, além de amplos, são extremamente complexos. A articulação do conhecimento científico e técnico somado ao conhecimento empírico da população certamente resultaram em práticas e políticas públicas mais acertadas e construtivas dentro do ambiente urbano. Mudanças são mais efetivas quando passam pela percepção e conscientização de todos os agentes envolvidos no processo.

\section{CONSIDERAÇÕES FINAIS}

A modernidade impulsionada pelo capitalismo está vinculada à lógica dos valores financeiros, altamente comerciais, tecnológicos, artificiais e urbanos, o que acaba determinando a exclusão da natureza da vida cotidiana, principalmente, da população urbana.

A substituição de elementos naturais da paisagem por obras de construção civil fundamentadas pelo asfalto, concreto e grandes edificações, contribuem para um desenvolvimento pouco harmonioso tendo reflexos negativos sobre a qualidade de vida da população e gerando uma crise entre as cidades e a natureza.

Contudo, é possível que a percepção e conscientização da população com relação a sua responsabilidade frente aos problemas ambientais, possibilitem uma 


\section{ANAP

participação mais efetiva da sociedade urbana, já que a maior parte da população mundial se concentra nas cidades.

A construção de cidades sustentáveis passa pela maior participação dos atores sociais vinculadas à problemática e a sua maior capacidade de influir sobre a resolução de problemas comuns.

É necessária ainda a compreensão de que natureza e o urbano não são antagônicos e que podem e devem coexistir dentro de uma sociedade. O planejamento urbano deve prever cada vez mais iniciativas para diminuir ao máximo os impactos ambientais causados pela intensa ação antrópica no meio urbano, dando especial atenção ao excesso de pavimentação do solo e ao aumento da arborização nas ruas e parques urbanos.

Em tempos onde o discurso de preservação ambiental é tão frequente e intenso, a percepção social sobre a necessidade de manutenção ou revitalização de áreas verdes nos centros urbanos parece ainda pouco notada pela população, embora seja extremamente importante para a sustentabilidade urbana e para o aumento da qualidade de vida dos habitantes das cidades.

\section{REFERÊNCIAS}

BECK, U. A reinvenção da política: rumo a uma nova teoria da modernização reflexiva. In: Modernização Reflexiva: Política, Tradição e Estética na Ordem Social Moderna. Tradução de Magda Lopes. São Paulo: UNESP, 1997. p: 11 a 52.

FOSTER, J. B. A ecologia de Marx: Materialismo e Natureza. Tradução Maria Tereza Machado. Rio de Janeiro: Civilização Brasileira, 2005. p. 201 a 246.

GUIMARÃES, R. P. A ética da sustentabilidade e a formulação de políticas de desenvolvimento. In: VIANA, G; SILVA, MARINA; DINIZ, N. (orgs). 0 desafio as 


\section{ANAP Brasil \\ ISSN 1904-3240 v. 6, n. 7}

\section{R E V IST A C I E N TÍF I C A JULHO/2013}

sustentabilidade: um debate socioambiental no Brasil. São Paulo: Editora Fundação Perseu Abramo, 2001. p: 43 a 68.

HANNIGAN, J. A. Sociologia ambiental: a formação de uma perspectiva social. Lisboa: Instituto Piaget, 1995.

LEFF, E. Saber Ambiental: Sustentabilidade, Racionalidade, Complexidade, Poder. $7^{\underline{a}}$ Ed. Tradução Lucia Mathilde Orth. Petrópolis: Vozes, 2009.

MELLAZO, G. C. A percepção ambiental e educação ambiental: uma reflexão sobre as relações interpessoais e ambientais no espaço urbano. Olhares \& Trilhas, Uberlândia, n. 6, p. $45-51,2005$.

MONICO, Ilza Maria. Árvores e arborização urbana na cidade de Piracicaba/SP: um olhar sobre a questão à luz da educação ambiental. 2001. 165 f. Dissertação (mestrado) Escola Superior de Agricultura "Luiz de Queiroz", Universidade de São Paulo, Piracicaba, 2001.

STEFFEN, Monica. Respostas públicas, sucesso e fracasso no gerenciamento de riscos. Desenvolvimento e Meio Ambiente, Curitiba, n. 5, p. 39-48, 2002.

TOURAINE, A. Crítica da modernidade. $6^{\underline{a}}$ ed. Tradução Elias Ferreira Edel. Petrópolis: Vozes, 1994.

TUAN, Yi-Fu. Topofilia: um estudo da percepção, atitudes e valores do meio ambiente. São Paulo: Difel, 1980. 